\title{
Surgical Treatment Compared to Conservative Treatment in Remission of Pain and Hyposthesia in Tarsal Tunnel Syndrome - Systematic Review
}

\section{Tratamento cirúrgico comparado ao tratamento conservador na remissão da dor e hipoestesia na síndrome do túnel do tarso - Revisão sistemática}

\author{
Márcio de Mendonça Cardoso4일 Ricardo de Amoreira Gepp ${ }^{4(0)}$

\footnotetext{
${ }^{1}$ Department of Neurosurgery, Hospital Vila da Serra, Nova Lima, MG, Brazil

2 Department of Neurosurgery, Hospital Aroldo Tourinho, Montes

Claros, MG, Brazil

${ }^{3}$ Department of Medicine, Universidade Funorte, Montes Claros, MG,

Brazil

${ }^{4}$ Department of Neurological Surgery, Sarah Network of

Rehabilitation Hospitals, Brasília, DF, Brazil
}

Marcelo José da Silva de Magalhães ${ }^{1,2,30}$ lara Cristina Vieira Ribeiro ${ }^{30}$

Address for correspondence Marcelo José da Silva de Magalhães, MD, Hospital Vila da Serra, Belo Horizonte, Minas Gerais 34000-000, Brazil (e-mail: marcelo7779@yahoo.com.br).

Arq Bras Neurocir 2022;41(2):e145-e152.

\section{Abstract \\ Keywords \\ - tarsal tunnel syndrome \\ - posterior tibial nerve \\ - conservative treatment \\ - surgical treatment.}

Introduction Tarsal tunnel syndrome (TTS) is caused by compression of the posterior tibial nerve.

Objective To evaluate the effectiveness of surgical treatments compared to conservative treatments in reducing the symptoms of the syndrome.

Methods The PubMed, Lilacs, Cochrane Library, and PEDro databases were used for this review.

Results Only 11 articles were selected.

Conclusion The most common causes of TTS identified were presence of ganglia, bone prominence causing a talocalcaneal collision, trauma, varicose and idiopathic veins. The main symptom was pain in the medial plantar region and paresthesia that can radiate to the fingers or to the calf. Most patients have a positive Tinel sign upon physical examination. Electrodiagnostic test usually shows the presence of latency in sensory nerve conduction. There is no consensus suggesting that a longer time between diagnosis and surgical treatment leads to worse prognosis. In the group of operated patients, the ones who benefited most from the procedure were those who had a structure such as ganglion, cysts, or varicosities causing compression. The most received

July 15, 2021

accepted after revision

October 13, 2021

published online

March 3, 2022
DOI https://doi.org/

$10.1055 / \mathrm{s}-0042-1742425$.

ISSN $0103-5355$. (c) 2022. Sociedade Brasileira de Neurocirurgia. All rights reserved. This is an open access article published by Thieme under the terms of the Creative Commons Attribution-NonDerivative-NonCommercial-License, permitting copying and reproduction so long as the original work is given appropriate credit. Contents may not be used for commercial purposes, or adapted, remixed, transformed or built upon. (https://creativecommons.org/ licenses/by-nc-nd/4.0/)

Thieme Revinter Publicações Ltda., Rua do Matoso 170, Rio de Janeiro, RJ, CEP 20270-135, Brazil 
Resumo

Palavras-chave

- síndrome do túnel do tarso

- nervo tibial posterior

- tratamento conservador

- tratamento cirúrgico. cited surgical complications were postsurgical wound infection, wound dehiscence, and calcaneus hypoesthesia. Regarding surgical techniques, the release of the posterior tibial nerve via endoscopy had a favorable outcome in relation to the symptoms of pain and hypoesthesia, with no reports of infection of the operative site in the articles identified in this review. We observed a rate of good or excellent pain control of $68 \%$ $(n=204)$ for open surgery $(n=299), 100 \%(n=8)$ for endoscopic surgery $(n=8)$, and $7 \%(n=2)$ for conservative treatment $(n=28)$.

Introdução A síndrome do túnel do tarso (STT) é causada pela compressão do nervo tibial posterior.

Objetivo Avaliar a eficácia dos tratamentos cirúrgicos em comparação aos conservadores na redução dos sintomas da síndrome.

Métodos Foram utilizados as bases de dados PubMed, Lilacs, Cochrane Library e PEDro.

Resultados Apenas 11 artigos foram selecionados.

Conclusão As causas mais comuns de STT identificadas foram presença de gânglios, proeminência óssea causando colisão talocalcânea, trauma, varizes e veias. O principal sintoma foi dor na região plantar medial e parestesia, que pode irradiar para os dedos ou panturrilha. A grande maioria dos pacientes apresenta um sinal de Tinel positivo no exame físico. O teste eletrodiagnóstico geralmente mostra a presença de latência na condução nervosa sensorial. Não há consenso de que o maior tempo entre o diagnóstico e o tratamento cirúrgico leva a um pior prognóstico. No grupo de pacientes operados, os que mais se beneficiaram com o procedimento foram aqueles que apresentavam estrutura como gânglio, cistos ou varicosidades causando compressão. As complicações cirúrgicas mais citadas foram infecção da ferida operatória, deiscência da ferida e hipoestesia do calcâneo. A cirurgia endoscópica teve evolução favorável em relação aos sintomas de dor e hipoestesia, não havendo relato de infecção do sítio operatório. Observou-se que a taxa de bom ou excelente controle da dor foi de $68 \%$ $(n=204)$ para cirurgia aberta $(n=299), 100 \%(n=8)$ para cirurgia endoscópica $(n=8)$, e $7 \%(n=2)$ para o tratamento conservador $(n=28)$.

\section{Introduction}

The tarsal tunnel syndrome (TTS) was implemented in 1962 by Charles Keck, who published the first clinical cases on the topic and, in that same year, Lam published an article detailing the syndrome. ${ }^{1-3}$ The compression of the tibial nerve and its branches has a close anatomical relationship with its adjacent structures: bone, muscle, and vascular structures (Image 1).

The flexor retinaculum extends between the medial malleolus and the medial side of the calcaneus supporting the tendons of the posterior tibial muscles, the long flexor of the fingers, the long flexor of the hallux, and the vascular structures-posterior tibial artery and vein. The bony floor and the deep fascia of the abductor hallucis muscle form the tunnel of the distal tarsus. ${ }^{4}$

Symptoms include pain and paresthesia in the posterior region of the foot that can radiate to the plantar region. Initially, pain complaints tend to occur after strenuous physical activity, prolonged standing periods, and use of certain types of shoes, but they tend to improve with rest. $^{3,5}$ The clinical diagnosis can be reinforced by the posi- tivity of the Tinel signal and due to the presence of changes in nerve conduction at electroneuromyography (ENMG). ${ }^{3-5}$

Many causes can contribute to the onset of the disease: fractures or dislocations involving the talus, calcaneus or medial malleolus, ganglion cysts, tumors, hypothyroidism, and inflammatory causes, such as rheumatoid arthritis and diabetes mellitus. ${ }^{3,5-10}$

Tarsal tunnel syndrome is the fifth most discussed compressive disease in the literature; however, there are still controversies in relation to treatment since opinions are greater than the evidence when it comes to choosing surgical treatment or maintaining conservative measures and what to do in cases of recurrence. Therefore, the present review aims to evaluate the efficacy of surgical treatment, compared with conservative treatment, in reducing the symptoms of TTS.

\section{Methods}

\section{Guiding question}

Is surgical treatment more effective in remission of pain and hypoesthesia in TTS compared to conservative treatment? (-Table 1) 


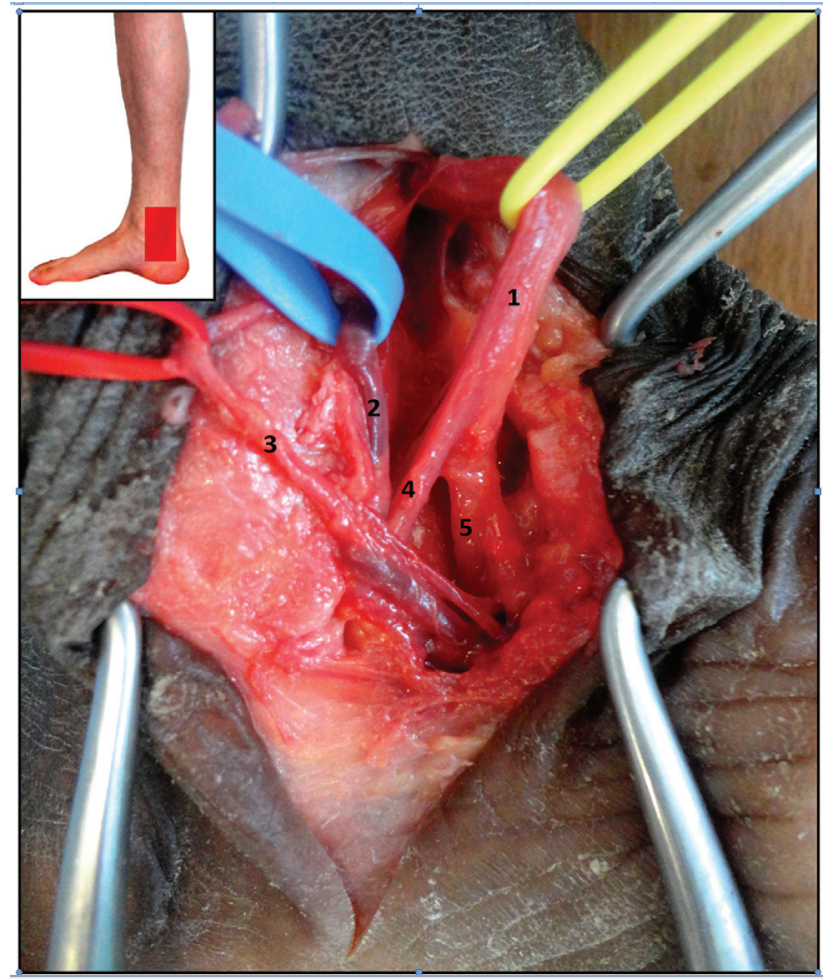

Image 1 Tibial nerve at the level of the medial malleolus in the right lower limb. Note that the flexor retinaculum was sectioned, exposing the division of the tibial nerve into the medial and lateral plantar nerve. The posterior tibial vein was isolated through the blue strip, and the posterior tibial artery through the red strip. Image kindly provided by Magalhães MJS. Neuroanataomia dos nervos periféricos. 1st edition. Brazil. Independently published. 2021. 1-Tibial nerve. 2Posterior tibial vein. 3-Posterior tibial artery. 4-Medial plantar nerve. 5-Lateral plantar nerve.

Table 1 Construction of the guiding question

\begin{tabular}{|l|l|l|}
\hline $\mathbf{P}$ & Population & Tarsal tunnel syndrome patients \\
\hline $\mathbf{I}$ & Intervention & Surgical treatment \\
\hline $\mathbf{C}$ & Control & Conservative treatment \\
\hline $\mathbf{O}$ & Outcome & Remission of pain and hypoesthesia \\
\hline
\end{tabular}

\section{Eligibility criteria and variables}

Only clinical studies with and without randomization were selected for the construction of the systematic review. We also opted for studies with a minimum of 3 months of followup after intervention and that used the following diagnostic criteria: clinical symptoms, positive Tinel signal, and/or altered electrodiagnostic study. All surgical techniques were included, and all conservative treatments were considered. Two researchers independently searched the databases, and another was the tiebreaker.

The variables studied are the complementary exam used for diagnosis, treatment modality, number of patients enrolled, symptoms presented, outcome after treatment, and complications.

Studies that did not address the treatment of patients were not considered, neither were those that included
Table 2 Keywords used in the researched databases with last access on July 21,2020

\begin{tabular}{|l|l|l|}
\hline Data base & Keywords & $\begin{array}{l}\text { Number } \\
\text { of articles } \\
\text { found }\end{array}$ \\
\hline PubMed & $\begin{array}{l}\text { syndrome, tarsal tunnel OR tibial } \\
\text { neuropathy OR posterior tibial nerve } \\
\text { neuralgia AND tarsal, tunnel } \\
\text { syndrome AND surgical interventions } \\
\text { AND surgical treatment AND } \\
\text { conservative treatment. }\end{array}$ & 8 \\
\hline Lilacs & $\begin{array}{l}\text { tarsal tunnel syndrome [Subject } \\
\text { descriptor] or sindrome do tunel do } \\
\text { tarso [Subject descriptor] or } \\
\text { síndrome del túnel tarsal [Subject } \\
\text { descriptor] }\end{array}$ & 25 \\
\hline $\begin{array}{l}\text { PEDro } \\
\text { (Physiotherapy } \\
\text { Evidence } \\
\text { Database) }\end{array}$ & $\begin{array}{l}\text { Tarsal tunnel syndrome } \\
\text { Library }\end{array}$ & PEDro: 2 \\
\hline Cochrane & Cochrane: 17 & \\
\hline
\end{tabular}

patients with diabetic polyneuropathy, leprosy, tendinopathies, and painful syndromes involving other nerves of the foot. This strategy was used to reduce confusion bias.

\section{Reasoning}

After a literature search in the Cochrane Library, PubMed and SciElo databases, no previous published studies were found that definitively answered the question, which corroborates the relevance of the study in question.

\section{Source of data and search}

The databases used were PubMed, Lilacs, Cochrane Library, and Physiotherapy Evidence Database (PEDro), with the date of the last access being July 21, 2020. The bibliography of the articles found was also analyzed in search of other relevant articles, with the last search being on September 4, 2020. The date of publication and the language of the study were not considered as criteria for the selection of articles. (-Table $\mathbf{2}$ )

\section{Data collection process}

After identifying the articles available in the databases, the title and abstract were initially read, thus resulting in a sample of 52 articles. Then, the Mendeley desktop reference manager was used to assist in the selection of studies. From the complete reading of the texts, 11 articles were chosen to compose the research. (-Figure 1)

\section{Risk of bias}

After analyzing the selected articles, some significant differences were found. Among them, we can mention the time interval between diagnosis and the beginning of treatment, the etiology of nerve compression and the evaluation of the therapeutic response. It is known that such situations can 


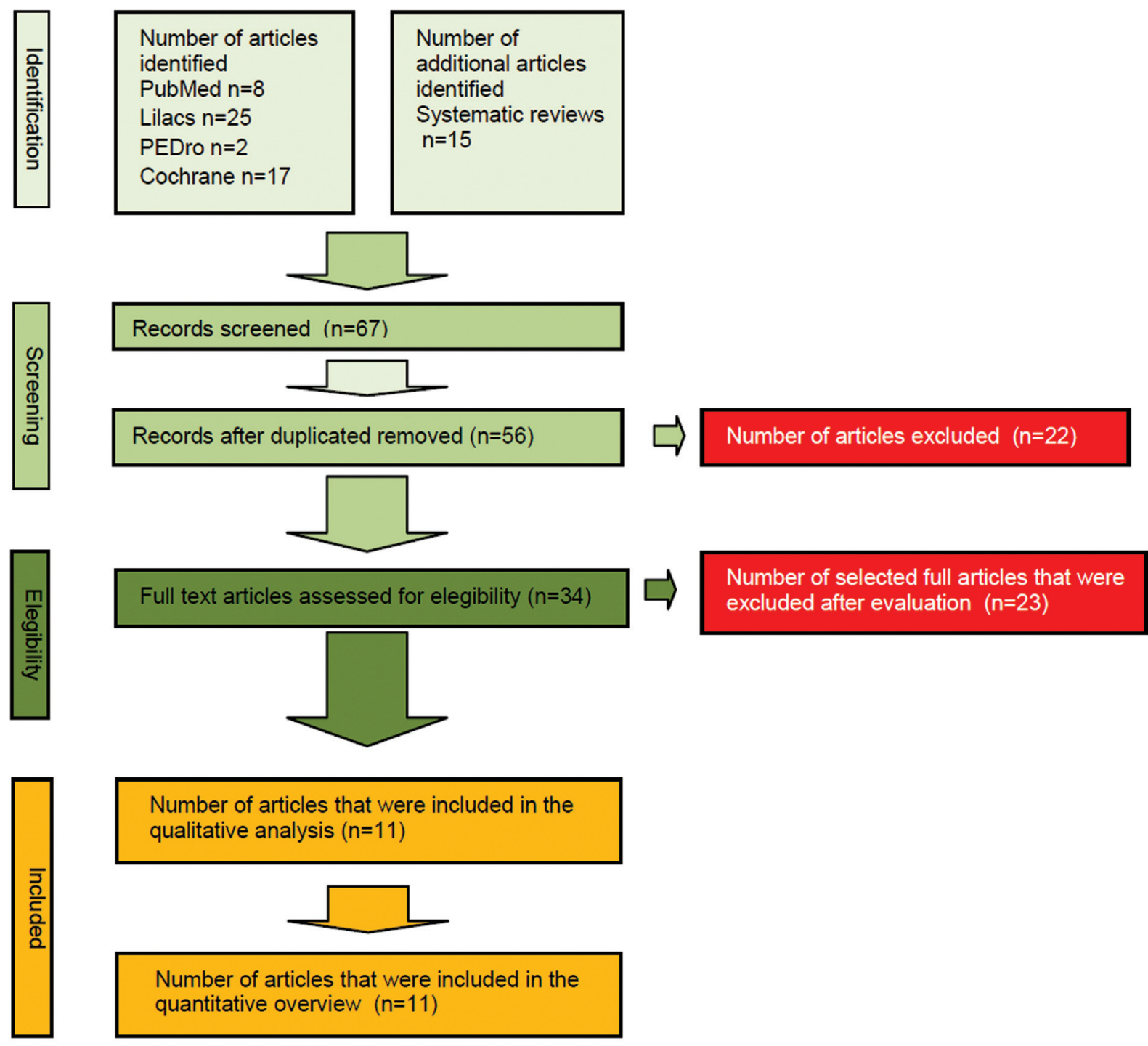

Fig. 1 Data collection

generate bias when comparing the effectiveness of the treatment.

There was a bias both in the choice of articles (different levels of evidence) as well as in the size and characteristics (gender, age, comorbidities) of the studied samples. In view of the management proposed in the different studies, there was no standardization between the types of conservative treatment and surgical techniques used, which may compromise the reliability of this systematic review.

\section{Results}

Description of the studies

Two case reports were found (SETTANNI, 1994; CHON, 2014). Settanni et al. (1994) evaluated 7 female patients, with clinical and ENMG evidence of TTS, who had previously undergone some type of conservative treatment. The seven patients underwent open surgery, two of which were bilateral. There was improvement in pain and hypoesthesia in three, improvement in pain and partial recovery of hypo- esthesia in three, and one loss to follow-up. In the study by Chon et al. (1994), only 2 patients (one woman and one man) were evaluated, with the presence of a positive Tinel signal and an altered ENMG. Only one of them had a history of open surgery for decompression of the tibial nerve, with no improvement in pain. After the pulsed radiofrequency, the patients were followed for a period of 8 to 12 months, with good response (control of pain and reduction of hypoesthesia). ${ }^{9,11}$

In addition to these, 9 clinical trials were analyzed (TAKAKURA et al., 1991; PFEIFFER et al.,1994; BABA et al., 1997; KOHNO et al., 2000; SAMMARCO et al., 2003; FLORES, 2005; JEROSCH et al., 2006; KRISHAN et al., 2006; KAVALAK et al., 2011). ${ }^{5-8,10,12-15}$

In the study of Kavalak et al. (2011), 28 patients were randomly divided into 2 groups. In the control group, the patients underwent a 6 -week physical therapy program at home, while in the other, patients received, in addition to the physical therapy program, nerve mobilization exercises. Before starting the treatment, the patients were evaluated 
for muscle strength and range of motion. All of them had clinical manifestations compatible with TTS, and the Tinel signal was present in most of them. At the end of the 6 months, both groups were reevaluated, and an increase in muscle strength and reduced pain was found in both groups, but improvement in sensory parameters was reported only in the test group. ${ }^{12}$

Another study by Krishan et al. (2006) involved 20 patients, 11 with ulnar sulcus syndrome, 8 with TTS, and 1 with meralgia paresthesia. All patients underwent surgery with an integrated endoscopic technique. Of the eight patients with TTS, three were female and five were male. The presence of classic symptoms of nerve compression, failure of conservative treatment, altered ENMG, and nonviolated anatomical region were used as selection criteria. The follow-up time varied between 3 and 28 months, and the results found were: absence of pain and paresthesia in five feet, and improvement of pain and reduction of paresthesia in three. ${ }^{7}$

The study conducted by Jerosch et al. (2006) addressed 77 surgical decompressions performed on 75 patients ( 54 women and 21 men), with the mandatory criterion of a minimum period of 6 months of conservative treatment. The results were evaluated according to pain at rest, pain during walking, and weakness, and, according to the modified American Orthopedic Foot and Ankle Society (AOFAS) score, there was a reduction in pain at rest in 53 patients, and improvement in subjective muscle weakness in 6 . Only three feet had superficial infection of the postoperative wound. ${ }^{5}$

The study conducted by Flores (2005) consisted of a retrospective analysis of nine patients diagnosed with idiopathic TTS, in which open surgery was performed with the aid of a surgical magnifying glass. The nine feet showed improvement in pain and paresthesia; however, five had postoperative wound infection, and six had wound dehiscence. $^{8}$

Kohno et al. (2000) published the surgical results of complete resection of the flexor retinaculum associated with the insertion of a fat graft between the dissected vessels and the nerve. This procedure was performed on 12 feet of 9 patients diagnosed with idiopathic TTS. Most patients had a good response in the first 3 months of postoperative followup. ${ }^{6}$

In another study by Sammarco et al. (2003), 72 feet underwent open surgery for decompression of the tibial nerve. The diagnosis was made in the presence of clinical signs and symptoms and altered ENMG; 31 patients had a history of foot trauma. Postsurgical follow-up lasted an average of 58 months. The Maryland Foot Score (MFS) was used before and after the operation, with the average score obtained before the procedure being 64/100, and after $80 / 100$. The AOFAS score was used only in the postoperative period, and the average was also 80/100. Patients presenting with symptoms for less than 1 year had the highest score on both scores. $^{10}$

Baba et al. (1997) described 34 patients with TTS, with the condition being bilateral in 3 cases. Of these, 9 were male, and 25 were female, with an average age of 41 years. Open surgery with excision of compressive structures was performed. There was no report of previous conservative treatment. The average follow-up period was 3.8 years, and the multivariate analysis showed that the results are influenced by the presence of fibrosis around the nerve, severity of the preoperative condition, history of ankle sprain and heavy work. $^{13}$

Takakura et al. (1991) linked the causes of TTS to the response to treatment, with the best results in patients in whom some structure was causing compression, such as coalition and tumor. ${ }^{14}$ These authors described 45 patients with TTS. Of these, 21 were male, and 24 were female. All patients underwent surgery with follow-up time varying between 1 and 13 years. Good pain control was obtained in patients with diagnosis of tarsal coalition, tumor, and ganglion. Fair pain control was observed in patients with idiopathic TTS and previous trauma.

Finally, the work of Pfeiffer et al. (1994) reviewed the clinical results of 30 patients (32 feet) who underwent surgical decompression of the posterior tibial nerve in the period between 1982 and 1990. The average duration of the segment was 31 months, and the results obtained were: $44 \%$ of the feet benefited from the surgery with good or excellent results; $38 \%$ had unsatisfactory results, with no long-term pain relief; pain reduced by $19 \%$, but patients still complained about paresthesia; and $13 \%$ of the feet had complications in the surgical wound. Based on these results, the authors concluded that unless there is a known structure causing compression of the tibial nerve, surgery should be recommended with caution. ${ }^{15}$

We identified a rate of good or excellent pain control of $68 \%(n=204)$ for open surgery $(n=299), 100 \%(n=8)$ for endoscopic surgery $(n=8)$, and $7 \%(n=2)$ for conservative treatment $(\mathrm{n}=28)^{5-10,12-15}$

\section{Discussion}

The research considered 11 articles, 2 case reports and 9 clinical trials, with a total of 309 participants (337 feet evaluated). As for the etiology of the syndrome, it can be primary (idiopathic) or secondary to a series of diseases in the hindfoot region. The most common causes identified were presence of ganglia, bone prominence causing a talocalcaneal collision, trauma, varicose, and idiopathic veins. ${ }^{16}$

The clinical manifestations may differ according to the disease that causes the compression; however, most patients presented the classic picture of pain in the medial plantar region, and paresthesia that can radiate to the fingers or to the calf (Valleix phenomenon). Pain tends to worsen at night. ${ }^{16,17}$

The diagnosis was based on clinical history and physical examination, the vast majority of patients have a positive Tinel sign, some have a positive tibial nerve compression maneuver, and others report improvement in pain and paresthesia with posterior tibial nerve block with $3 \mathrm{ml}$ of $1 \%$ lidocaine. $^{16}$

As for complementary exams, the presence of latency in sensory nerve conduction is the most common finding in 
electrodiagnostic tests, because, in the initial stages, the damage is mainly sensory, due to the greater susceptibility of the sensitive fibers to injury. Kohno et al. (2000) performed the measurement of the sensory nerve conduction VELOCITY (NCV) in 5 of his patients, and only 2 presented slow VCS, less than $35 \mathrm{~m} / \mathrm{s}$. No study has been able to correlate the results of electrodiagnostic tests with the results obtained after the surgical procedure, so these tests should only be used as an aid to diagnosis, and the presence of a normal test does not rule out the presence of TTS. 6,17

Imaging exams play an important role for the identification of secondary etiologies of TTS. A simple foot X-ray can identify fractures and bony prominences in the vicinity of the tarsal tunnel. Magnetic resonance imaging is the most suitable for assessing the structures close to the flexor reticulum and to identify those that may be causing the compression of the posterior tibial nerve or one of its branches. In patients complaining of low back pain associated with pain in the foot radiating to the calf, a magnetic resonance imaging (MRI) of the lumbosacral spine should be requested to perform a differential diagnosis with S1 radiculopathy. ${ }^{16}$

The time of disease evolution was quite variable between the articles, some authors mentioned as an eligibility criterion that the patient must have undergone at least a few months of conservative treatment before being submitted to the surgical procedure. ${ }^{5,6}$

Regarding surgical techniques, the release of the posterior tibial nerve via endoscopy had a favorable outcome in relation to the symptoms of pain and hypoesthesia, with no reports of infection of the operative site. ${ }^{7}$ - Table 3

In open surgeries, there is no consensus on the use of tourniquets during the procedure. Although the tourniquet is effective in reducing intraoperative bleeding, some authors argue that it alters neurovascular conditions, making it impossible for the surgeon to identify possible arteries or veins that may be responsible for compression. As for sedation, some studies have recommended the use of local anesthesia associated with mild sedation, so that the patient is able to alert the professional about pain irradiation at the time of surgery, which can assist in the correct identification of the affected nervous branch. According to Kohno et al. (2000), if during the surgical procedure no structure is found that may be causing the compression, a fat graft should be placed between the nerve and the vessels to prevent them from sticking later. ${ }^{6,8}$ - Table 3

The follow-up period for patients varied between 3 months and 13 years. The tools used to assess patients' improvement after therapeutic intervention have not been standardized. One of the articles used more than one method, ${ }^{7}$ while others did not report the method used. $^{2,9}$ - Table 3

Among the strategies applied are validated scales (visual analogue scale, Maryland foot score, American Orthopedic Foot and Ankle Society - Ankle Kind foot score $)^{5,10-12}$; own scales $^{13,14}$; clinical evaluation (Tinel sign), and complementary exams (computed tomography [CT], MRI, ENMG). ${ }^{6,15}$ Some studies have suggested a follow-up of at least
12 months, as the patient may experience an improvement in pain and paresthesia initially, with recurrence a few months later. ${ }^{5,15}$

In the group of operated patients, the ones who benefited most from the procedure were those who had a structure such as ganglion, cysts, or varicosities causing compression; in other patients, the results were poor even with the authors reporting careful decompression of the nerve. Patients who had previously undergone some previous foot surgery, mainly involving the tibial nerve had a poor result, possibly due to the presence of fibrosis around the nerve ( - Table 3 ).

The most cited complications were postsurgical wound infection, wound dehiscence, and calcaneus hypoesthesia. - Table 3 Flores draws attention to the varied origin of the medial calcaneus branch, which may emerge from the tibial nerve or from one of its branches,. According to this author, during surgery, care must be taken to avoid injury to the calcaneus branch, which can result in hypoesthesia of the heel or formation of heel. ${ }^{8}$

The study of Chon et al. (1994) showed the effectiveness of ultrasound-guided pulsed radiofrequency, despite the small number of patients analyzed. It has shown promise, especially for patients who have not improved after surgical decompression, and also for those who the surgery has not been beneficial to (trauma, idiopathic origin, presence of plantar fasciitis, systemic inflammatory disease). However, more studies are needed. ${ }^{11}$

\section{Conclusion}

The most common causes of TTS identified were presence of ganglia, bone prominence causing a talocalcaneal collision, trauma, and varicose and idiopathic veins. The main symptoms were pain in the medial plantar region and paresthesia that can radiate to the fingers or to the calf. Most patients have a positive Tinel sign in their physical examination. The electrodiagnostic test usually shows the presence of latency in sensory nerve conduction. There is no consensus that a longer time between diagnosis and surgical treatment leads to worse prognosis. In the group of operated patients, the ones who benefited most from the procedure were those who had a structure such as ganglion, cysts, or varicosities causing compression. The tools used to assess patients' improvement after therapeutic intervention have not been standardized. The most cited surgical complications were: postsurgical wound infection, wound dehiscence, and calcaneus hypoesthesia. Regarding surgical techniques, the release of the posterior tibial nerve via endoscopy had a favorable outcome in relation to the symptoms of pain and hypoesthesia, with no reports of infection of the operative site. We identified a rate of good or excellent pain control of $68 \%(n=204)$ for open surgery $(n=299), 100 \%(n=8)$ for endoscopic surgery $(\mathrm{n}=8)$ and $7 \%(\mathrm{n}=2)$ for conservative treatment $(\mathrm{n}=28)$.

\section{0 - Funding Acknowledgements \\ This work was supported by PROCIÊNCIA.}




\begin{tabular}{|c|c|c|c|c|c|c|c|c|c|}
\hline 气̆ & 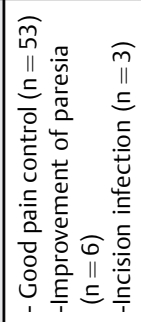 & 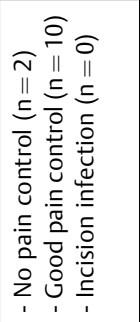 & 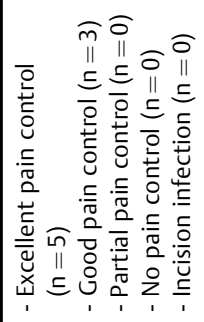 & 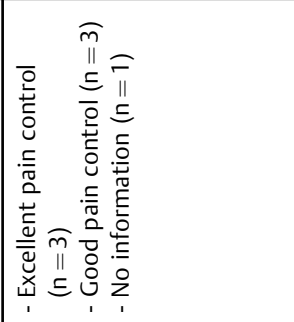 & 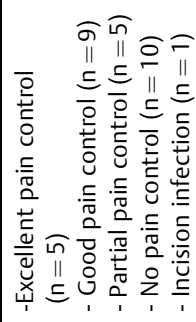 & 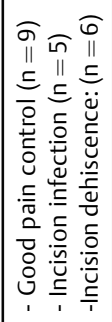 & 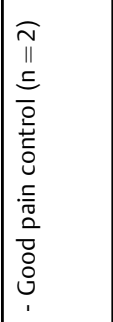 & 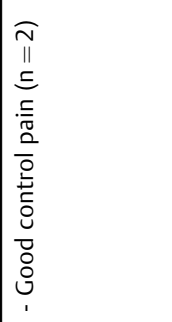 & 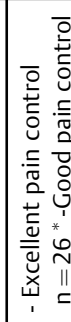 \\
\hline 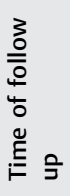 & 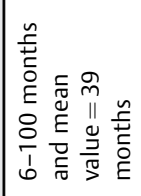 & 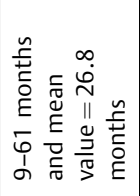 & 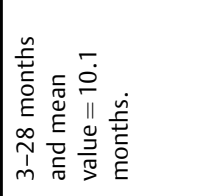 & 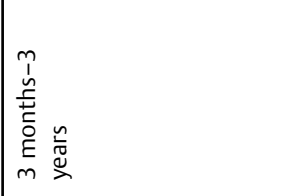 & 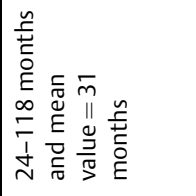 & 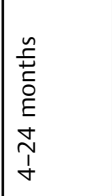 & 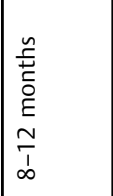 & 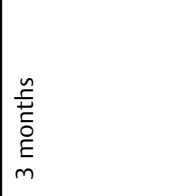 & 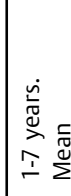 \\
\hline & 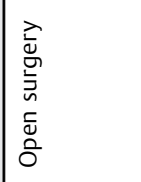 & 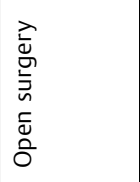 & 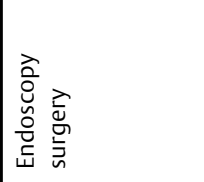 & 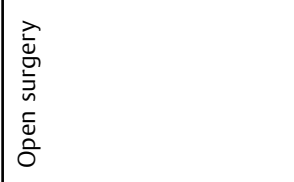 & 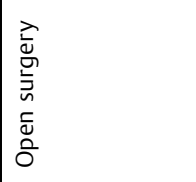 & 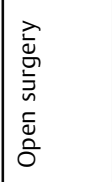 & 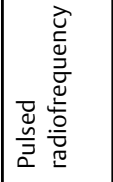 & 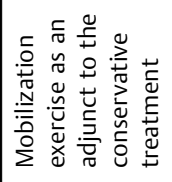 & 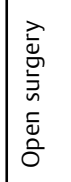 \\
\hline 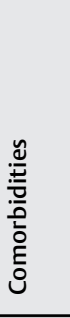 & I & 1 & 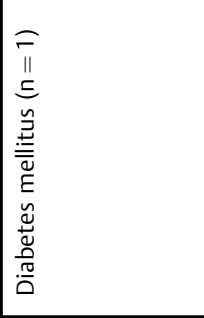 & 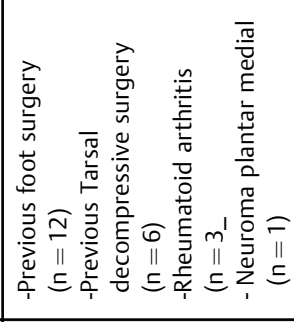 & $\mid 1$ & 1 & 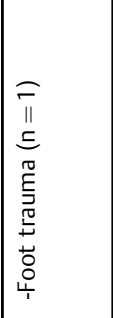 & 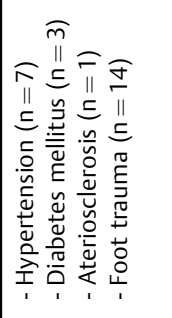 & 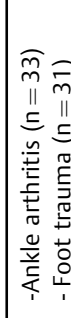 \\
\hline 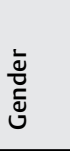 & 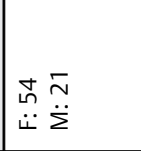 & 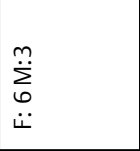 & 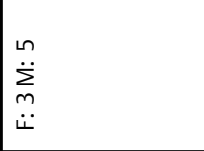 & 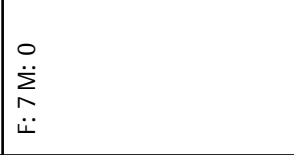 & $\begin{array}{l}0 \\
\ddot{\Sigma} \\
\dot{J} \\
\ddot{U}\end{array}$ & $\mid \begin{array}{l}\sim \\
\ddot{\sum} \\
\ddot{u}\end{array}$ & $\mid \underset{\ddot{\Sigma}}{\ddot{\dot{u}}}$ & $\mid \begin{array}{l}\stackrel{N}{1} \\
\ddot{z} \\
\dot{y} \\
\ddot{u}\end{array}$ & 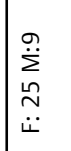 \\
\hline 娄 & 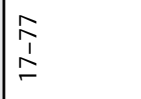 & $\begin{array}{l}\infty \\
i \\
i \\
\end{array}$ & 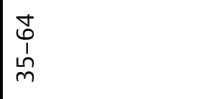 & $\begin{array}{l}\tilde{N} \\
\hat{\gamma} \\
\tilde{\gamma}\end{array}$ & $\begin{array}{l}\underset{N}{1} \\
\tilde{m}\end{array}$ & $\mid \begin{array}{c}\hat{n} \\
\hat{1} \\
\tilde{m}\end{array}$ & \begin{tabular}{|l}
0 \\
0 \\
1 \\
0 \\
in
\end{tabular} & $\mid \begin{array}{l}\hat{h} \\
\hat{j} \\
\hat{\sigma}\end{array}$ & $\begin{array}{l}m \\
\hat{j} \\
\dot{t}\end{array}$ \\
\hline 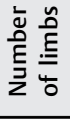 & $\vDash$ & $\simeq$ & $\infty$ & 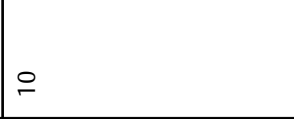 & $\stackrel{\sim}{m}$ & $a$ & $\sim$ & $\stackrel{\infty}{\sim}$ & $\hat{m}$ \\
\hline 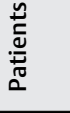 & $\stackrel{n}{\wedge}$ & $\sigma$ & $\infty$ & $r$ & $\stackrel{m}{m}$ & $a$ & $\sim$ & $\stackrel{\infty}{\sim}$ & $\stackrel{J}{m}$ \\
\hline 总 & 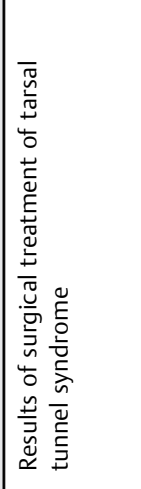 & 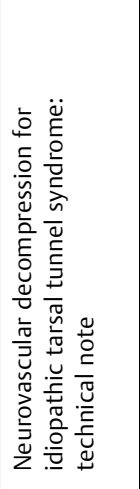 & 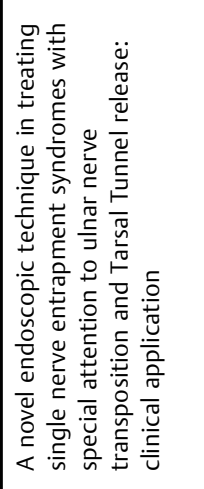 & 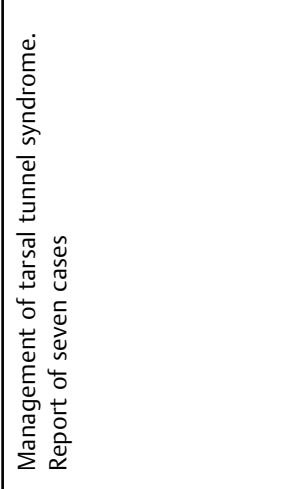 & 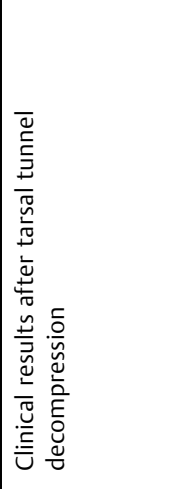 & 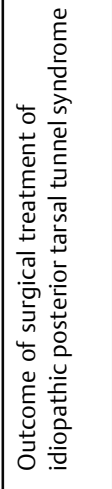 & 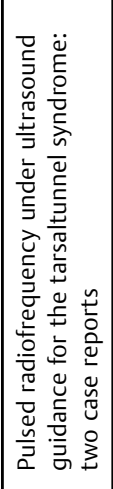 & 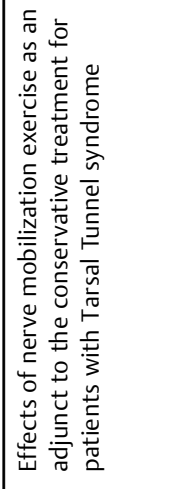 & 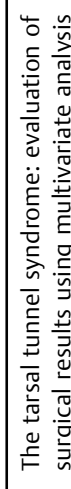 \\
\hline 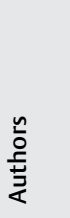 & 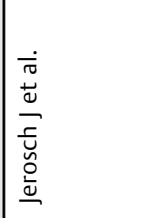 & 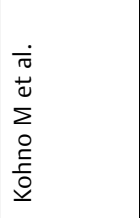 & 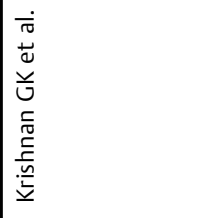 & 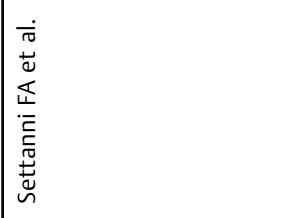 & 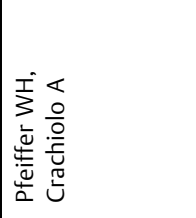 & 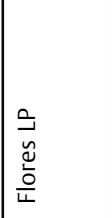 & 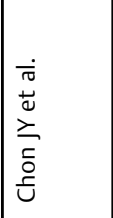 & 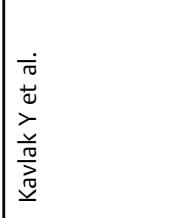 & 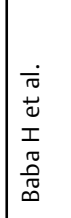 \\
\hline
\end{tabular}




\begin{tabular}{|c|c|c|c|}
\hline 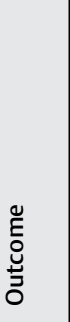 & 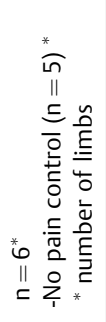 & 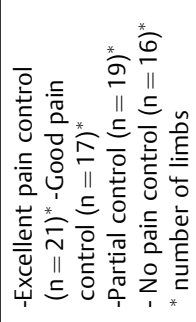 & 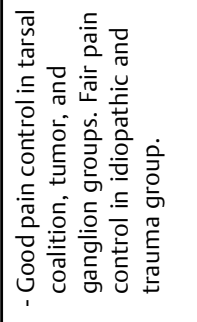 \\
\hline 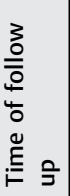 & 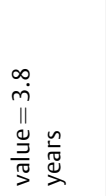 & 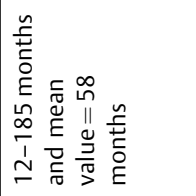 & 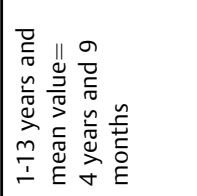 \\
\hline 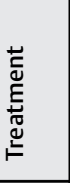 & & 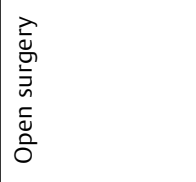 & 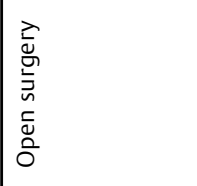 \\
\hline 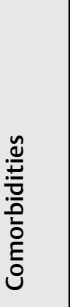 & 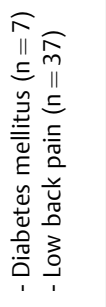 & 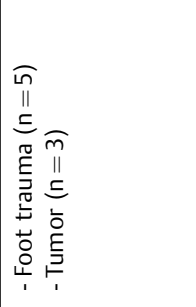 & 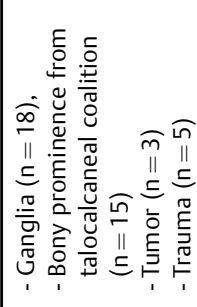 \\
\hline 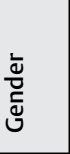 & & $\begin{array}{l}\infty \\
\ddot{\sum} \\
\dot{y} \\
\dot{j} \\
\dot{i}\end{array}$ & 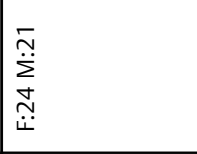 \\
\hline 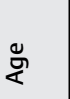 & & 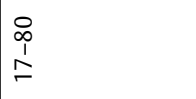 & $\begin{array}{l}\pi \\
\vdots \\
0\end{array}$ \\
\hline 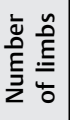 & & $\approx$ & in \\
\hline 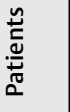 & & $\widetilde{\sigma}$ & ฆุ \\
\hline 苋 & & 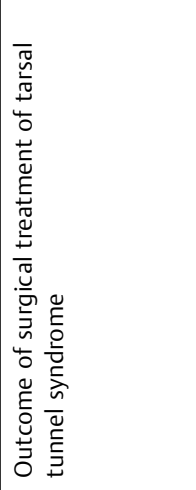 & 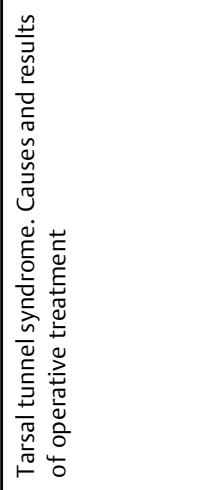 \\
\hline 蒿 & & 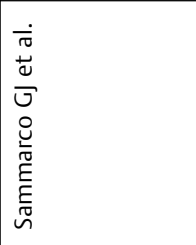 & 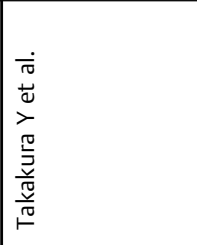 \\
\hline
\end{tabular}

\section{Conflict of Interests}

The authors have no conflict of interests to declare.

\section{References}

1 Torres AL, Ferreira MC. Study of the anatomy of the tibial nerve and its branches in the distal medial leg. Acta Ortop Bras 2012;20 (03):157-164

2 López-Gavito E, Parra-Téllez P, Cornejo-Olvera R, Vázquez-Escamilla J. Tarsal tunnel syndrome. Review of the topic as a result of one case. Acta Ortop Mex 2014;28(03):197-202

3 Lau JT, Daniels TR. Tarsal tunnel syndrome: a review of the literature. Foot Ankle Int 1999;20(03):201-209

4 Moraes Fllho DC, Galbiatti JA, Fialho HSA. Avaliação anatômica do túnel do tarso. Rev Bras Ortop 2000;35(08):282-289

5 Jerosch J, Schunck J, Khoja A. Results of surgical treatment of tarsal tunnel syndrome. Foot Ankle Surgery. 2006;12(04):205-208

6 Kohno M, Takahashi H, Segawa H, Sano K. Neurovascular decompression for idiopathic tarsal tunnel syndrome: technical note. J Neurol Neurosurg Psychiatry 2000;69(01):87-90

7 Krishnan GK, Pinzer T, Schackert G. A Novel endoscopic technique in treating single nerve entrapment syndromes with special attention to ulnar nerve transposition and tarsal tunnel release: Clinical Application. Operative Neurosurgery; 2006:89-100

8 Flores LP. Resultados do tratamento cirúrgico da síndrome do túnel do tarso posterior idiopática. Arq Bras Neurocir. 2005;24 (04):144-150

9 Settanni FALeandro LM, Zuleta JA, Neri EA. Management of tarsal tunnel syndrome. Report of seven cases. Arq Neuropsiquiatr 1994;52(04):530-534

10 Sammarco GJ, Chang L. Outcome of surgical treatment of tarsal tunnel syndrome. Foot Ankle Int 2003;24(02):125-131

11 Chon JY, Hahn YJ, Sung CH, Jung SH, Moon HS. Pulsed radiofrequency under ultrasound guidance for the tarsal tunnel syndrome: two case reports. J Anesth 2014;28(06):924-927

12 Kavlak Y, Uygur F. Effects of nerve mobilization exercise as an adjunct to the conservative treatment for patients with tarsal tunnel syndrome. J Manipulative Physiol Ther 2011;34(07): 441-448

13 Baba H, Wada M, Annen S, Azuchi M, Imura S, Tomita K. The tarsal tunnel syndrome: evaluation of surgical results using multivariate analysis. Int Orthop 1997;21(02):67-71(SICOT)

14 Takakura Y, Kitada C, Sugimoto K, Tanaka Y, Tamai S. Tarsal tunnel syndrome. Causes and results of operative treatment. J Bone Joint Surg Br 1991;73(01):125-128

15 Pfeiffer WH, Cracchiolo A III. Clinical results after tarsal tunnel decompression. J Bone Joint Surg Am 1994;76(08):1222-1230

16 Franson J, Baravarian B. Tarsal tunnel syndrome: a compression neuropathy involving four distinct tunnels. Clin Podiatr Med Surg 2006;23(03):597-609

17 Cimino WR. Tarsal tunnel syndrome: review of the literature. Foot Ankle 1990;11(01):47-52 